\title{
Comparison of various techniques for the extraction of umbelliferone and herniarin in Matricaria chamomilla processing fractions
}

\author{
Maja Molnar, Nikolina Mendešević, Drago Šubarić, Ines Banjari and Stela Jokić
}

\begin{abstract}
Chamomile, a well-known medicinal plant, is a rich source of bioactive compounds, among which two coumarin derivatives, umbelliferone and herniarin, are often found in its extracts. Chamomile extracts have found a different uses in cosmetic industry, as well as umbelliferone itself, which is, due to its strong absorption of UV light, usually added to sunscreens, while herniarin (7-methoxycoumarin) is also known for its biological activity. Therefore, chamomile extracts with certain herniarin and umbelliferone content could be of interest for application in pharmaceutical and cosmetic products. The aim of this study was to compare the extracts of different chamomile fractions (unprocessed chamomile flowers first class, processed chamomile flowers first class, pulvis and processing waste) and to identify the best material and method of extraction to obtain herniarin and umbelliferone. Various extraction techniques such as soxhlet, hydrodistillation, maceration and supercritical $\mathrm{CO}_{2}$ extraction were used in this study. Umbelliferone and herniarin content was determined by high performance liquid chromatography (HPLC). The highest yield of umbelliferone $(11.80 \mathrm{mg} / 100 \mathrm{~g})$ and herniarin $(82.79 \mathrm{mg} / 100 \mathrm{~g})$ were obtained from chamomile processing waste using maceration technique with 50\% aqueous ethanol solution and this extract has also proven to possess antioxidant activity (61.5\% DPPH scavenging activity). This study shows a possibility of potential utilization of waste from chamomile processing applying different extraction techniques.
\end{abstract}

Keywords: Chamomile fractions, Herniarin, Umbelliferone, Extraction, Antioxidant activity

\section{Background}

Cultivation of medicinal and aromatic plants, especially chamomile (Matricaria chamomilla), has increased in recent years and large areas of Republic Croatia are designed specifically for this type of farming. Chamomile belongs to those drugs that experienced a wide medical application, mainly due to its anti-inflammatory, antiseptic and antispasmodic activity. Application fields of chamomile products include dermatology, stomatology, otolaryngology, internal medicine, in particular gastroenterology, pulmology, pediatry and radiotherapy [1]. Chamomile extracts can also be used in different

*Correspondence: stela.jokic@ptfos.hr

Faculty of Food Technology Osijek, Josip Juraj Strossmayer University of Osijek, Franje Kuhaca 20, 31000 Osijek, Croatia industries, which usually utilize only some parts of the plant and the rest is considered as waste.

Chamomile contains a large number of therapeutically interesting bioactive compounds, sesquiterpenes, flavonoids, coumarins and polyacetylenes being considered the most important ones [2,3]. In existing papers that deal with the content of chamomile coumarin compounds, seven coumarins (herniarin, umbelliferone, coumarin, isoscopoletine, scopoletine, esculetin, and fraxidin) were described [4-6], while Petrulova-Poracka et al. [7] have found skimmin, daphnin, daphnetin in anthodia and leaves. Plant coumarins, in general, are usually described as phytoalexins and are considered as plant defence compounds in biotic and abiotic stress conditions $[8,9]$. Content of herniarin and umbelliferone, as secondary metabolites in chamomile leaf rosettes, was 
proven to be higher when plant is subjected to abiotic stress [10] and Petrulova-Poracka et al. [7] found that umbelliferone in chamomille leaves is usually present in higher levels compared to anthodia (plant head). In addition, chamomile flowers also contain several coumarin compounds, herniarin and umbelliferone [7, 11-13], usually herniarin in greater amount compared to umbelliferone [14]. Redaelli et al. [14] investigated different parts of chamomile flower heads for herniarin and umbelliferone content and found that ligulate florets exhibit higher content of coumarins than other parts of the flower head.

Coumarin-related compounds exhibit antimicrobial and anti-inflammatory activity [15], while umbelliferone itself exhibits various biological properties, antioxidant activity in vitro, inhibition of HIV-1 replication and inhibition of cell proliferation of different human tumor cell lines $[16,17]$. Umbelliferone is often used in sunscreens as it strongly absorbs ultraviolet light at several wavelengths [18]. Herniarin is also well known for its various biological activities [19].

Bioactive compounds are often present in the plants in low concentration and are chemically sensitive. So it is very important to investigate the effectiveness of extraction method to recover these compounds from plant material [11], especially those parts that are considered as waste from chamomile processing. The traditional methods for the extraction of plant materials include steam distillation and organic solvent extraction using percolation, maceration or Soxhlet techniques [20]. In addition, there is a growing interest in alternative extraction technologies consuming less organic solvents, due to their toxicity and regulatory restrictions. One such "green technology" is supercritical carbon dioxide $\left(\mathrm{CO}_{2}\right)$ extraction which exhibit several advantages in the extraction of natural products from plant matrices. Extracts obtained using $\mathrm{CO}_{2}$ as the extraction solvent are solventfree/without any trace of toxic extraction solvents, with better retention of aromatic compounds, and are thereby highly valued [21].
A number of studies have reported the supercritical fluid extraction (SFE) of chamomile [20, 22-30] and most of the authors investigated composition of chamomile flowers $[14,20,26]$, while in this study we examined different chamomile fractions, containing different parts of chamomile, obtained during chamomile processing. These fractions include unprocessed chamomile flowers first class, processed chamomile flowers first class, pulvis and processing waste, respectively.

The various extraction techniques (soxhlet, hydrodestillation, maceration, supercritical $\mathrm{CO}_{2}$ extraction) were used for obtaining chamomile extracts which were further compared on the extraction yield, their antioxidant activity and umbelliferone content determined by high performance liquid chromatography (HPLC).

\section{Materials and methods Chemicals}

The purity of $\mathrm{CO}_{2}$ used for extraction was $99.97 \%(w / w)$ (Messer, Osijek, Croatia). DPPH and ethyl acetate were purchased from Sigma-Aldrich Chemie (Steiheim, Germany). Umbelliferone and herniarin were purchased from Dr. Ehrenstorfer GmbH (Augsburg, Germany) and standard purity was $99.9 \%$ as informed by supplier. All solvents were of analytical grade and purchased from J.T. Baker (PA, USA).

\section{Plant material}

The following samples of chamomile (Fig. 1) were used: unprocessed chamomile flowers First class, processed chamomile flowers first class, pulvis and processing waste obtained from the company Matricia Ltd. (ŠirokoPolje, Croatia) in year 2015.

Unprocessed chamomile flowers first class (Fig. 1a) are related to the samples obtained after cutting fresh chamomile using machine for cutting herbs.

Processed chamomile flowers first class (Fig. 1b) are obtained after cutting the stems from picked chamomile flowers. High capacity sieve separates flower heads from

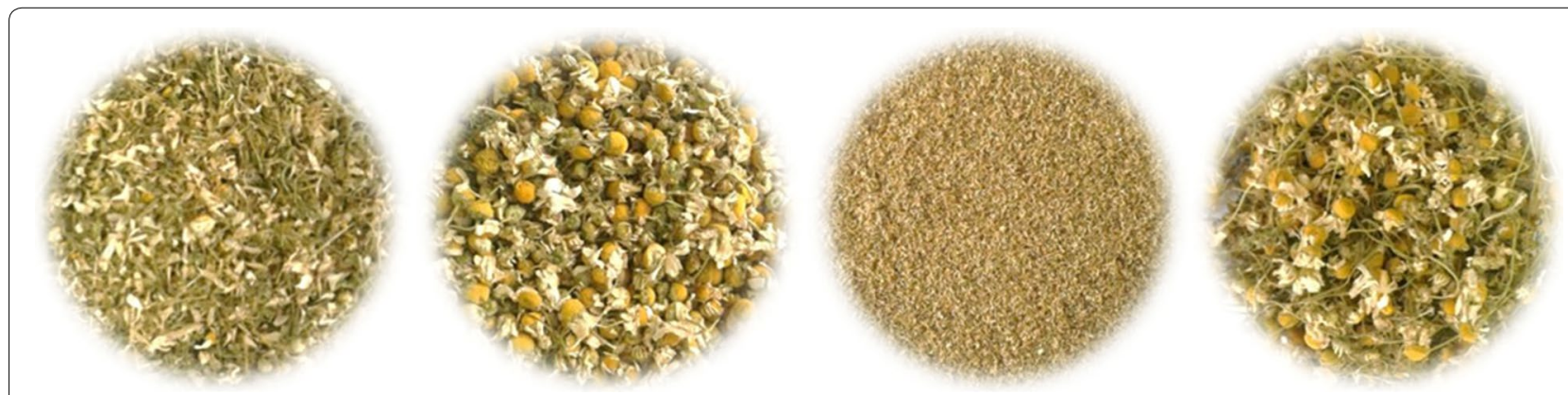

Fig. 1 Chamomile samples used in this study (a unprocessed chamomile flowers first class; $\mathbf{b}$ processed chamomile flowers first class; $\mathbf{c}$ pulvis; $\mathbf{d}$ processing waste) 
stems and pulvis. After that, samples are dried at temperature of around $30{ }^{\circ} \mathrm{C}$. The final product is a goodquality flowers without stems, with excellent shape and appearance.

Processing waste (Fig. 1c) are remaining after chamomile processing (without chamomile flower heads).

Pulvis (Fig. 1d) are flower parts released from the flower heads during manipulation, after the drying process.

Prior to extraction, the plant material was grounded using laboratory mill.

\section{Extraction procedures Soxhlet extraction}

A sample of $5.0 \mathrm{~g}$ of each plant material was extracted by $150 \mathrm{~mL} n$-hexane using a Soxhlet apparatus until totally depleted. The whole process took $8 \mathrm{~h}$. Furthermore, the solvent was evaporated under vacuum, and the obtained extracts were stored in a glass bottles at $4-6{ }^{\circ} \mathrm{C}$. The measurements were performed in triplicate.

\section{Maceration}

The $20.0 \mathrm{~g}$ of each dried grounded material were immersed into $100 \mathrm{~mL}$ of $50 \%$ aqueous ethanol solution. The system was left to soak for 5 days in the dark at room temperature and it was occasionally shaken. The alcoholic extract was then filtered through filter paper to eliminate any solid impurities and concentrated in rotary vacuum evaporator at $35{ }^{\circ} \mathrm{C}$ yielding a waxy material. Finally, the extracts were kept in the dark at $4-6{ }^{\circ} \mathrm{C}$ until tested. The measurements were performed in triplicate.

\section{Hydrodistillation}

The $100 \mathrm{~g}$ of each samples were used for hydrodistillation $(4 \mathrm{~h})$ in Clevenger type apparatus. The essential oil was dried over anhydrous $\mathrm{MgSO}_{4}$ and kept at $4-6{ }^{\circ} \mathrm{C}$ until further analysis. The measurements were performed in triplicate.

\section{Supercritical $\mathrm{CO}_{2}$ extraction}

The experiment was performed in SFE system explained in detail previously [31]. Each chamomile sample $(100 \mathrm{~g})$, respectively, was placed into the extractor vessel and the extracts were collected in a separator in previously weighed glass tubes at $1.5 \mathrm{MPa}$ and $25{ }^{\circ} \mathrm{C}$. The amount of extract obtained at regular intervals of time was established by weight using a balance with precision of $\pm 0.0001 \mathrm{~g}$. Extraction yield was expressed as \% ( $\mathrm{g}$ of extract/100 $\mathrm{g}$ of dried material). The extraction was performed at extraction conditions of $30 \mathrm{MPa}$ and $40{ }^{\circ} \mathrm{C}$. Dynamic extraction mode for SFE was used where supercritical $\mathrm{CO}_{2}$ continuously passed through the sample matrix (chamomile). The mass of dried material in extractor, the extraction time and $\mathrm{CO}_{2}$ mass flow rate were kept constant during experiments. The $\mathrm{CO}_{2}$ flow rate $(2 \mathrm{~kg} / \mathrm{h})$ was measured by a Matheson FM-1050 (E800) flow meter. Each extraction run lasted for $90 \mathrm{~min}$, since longer extraction times did not significantly increase the extraction yield (based on our preliminary experiments). The obtained extracts were kept at $4-6{ }^{\circ} \mathrm{C}$ until HPLC analyses. The measurements were performed in triplicate.

\section{Determination of umbelliferone and herniarin concentration by HPLC}

RP-HPLC method with UV detection was used for umbelliferone and herniarin determination in obtained extracts according to the application for used column. The example of HPLC chromatogram of the extract from processing waste obtained by Soxhlet technique is given at Fig. 2. HPLC analyses were performed on a Varian ProStar system (Varian Analytical Instruments, CA, USA) consisted of Varian ProStar 230 Solvent Delivery Module, ProStar 500 Column Valve Module and ProStar 330 Photodiode Array detector. System was coupled to a computer with the ProStar 5.5 Star Chromatography Workstation and PolyView 2000 V 6.0.

Chromatographic separation was obtained on a COSMOSIL 5C18-MA-II (NacalaiTesque, Inc., Kyoto, Japan) column, $150 \mathrm{~mm}$ long with internal diameter of $4.6 \mathrm{~mm}$.

Separation of analysed compounds was performed with gradient elution where distilled water was used as phase $\mathrm{A}$ and methanol as phase $\mathrm{B}$. The following gradient was used: $0-15 \mathrm{~min}, 60 \% \mathrm{~A}$ and $40 \% \mathrm{~B}$ phase; $15-20 \mathrm{~min}$, increasing the share of phase $\mathrm{B}$ to $80 \%$ and decreasing phase A to $20 \%$; $20-40$ min, holding $20 \% \mathrm{~A}$ and $80 \%$ $\mathrm{B}$ phase; $40-41$ min decreasing of $\mathrm{B}$ phase to $40 \%$ and increasing $\mathrm{A}$ phase to $60 \%, 41-50 \mathrm{~min}$, holding $60 \% \mathrm{~A}$ and $40 \% \mathrm{~B}$ phase. The flow rate was $1.0 \mathrm{~mL} / \mathrm{min}$, injection volume was $20 \mu \mathrm{L}$, UV detection wavelength $330 \mathrm{~nm}$ and chromatography was performed at room temperature. Standard stock solutions were prepared in a solvent and calibration was obtained at six concentrations (concentration range 1.0, 2.0, 5.0, 10.0, 20.0, $50.0 \mathrm{mg} / \mathrm{L}$ ). Linearity of the calibration curve was confirmed by $R^{2}=0.9996$ for umbelliferone. Umbelliferone limit of detection (LOD) was $0.16 \mathrm{mg} / \mathrm{L}$, limit of quantification (LOQ) was $0.52 \mathrm{mg} / \mathrm{L}$ and compound retention time was $13.37 \mathrm{~min}$. Linearity of the herniarin calibration curve was confirmed by $\mathrm{R}^{2}=0.9999$. Herniarin limit of detection (LOD) was $0.129 \mathrm{mg} / \mathrm{L}$, limit of quantification (LOQ) $0.4299 \mathrm{mg} / \mathrm{L}$ and compound retention time was $24.72 \mathrm{~min}$. Extracts were diluted in methanol HPLC grade, filtered through $0.45 \mu \mathrm{m}$ PTFE filters and subjected to HPLC analyses.

Concentration of umbelliferone and herniarin in plant extracts $(\mu \mathrm{g} / \mathrm{mL})$ determined by HPLC analysis was used 


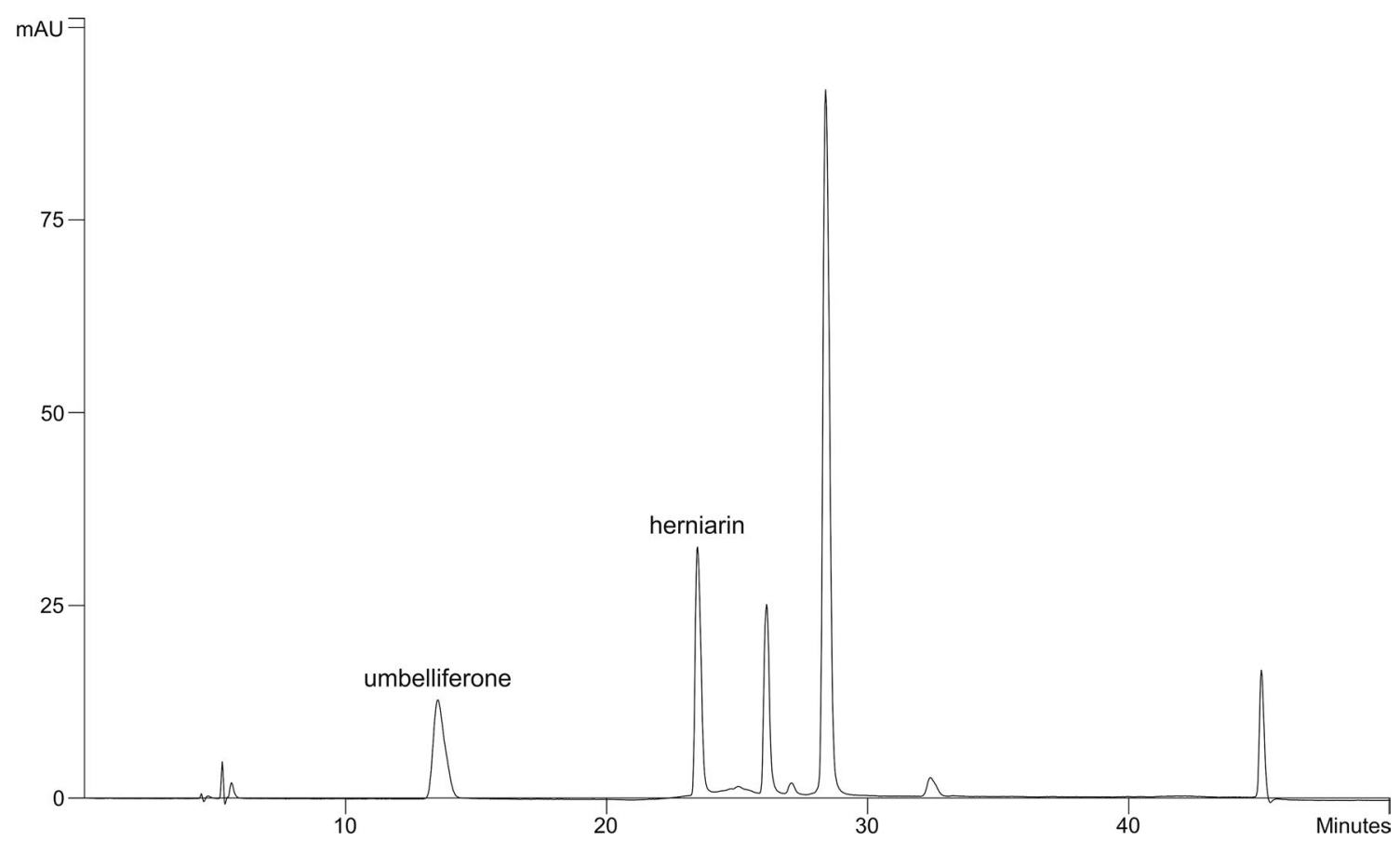

Fig. 2 HPLC chromatogram of chamomile extract

for calculation of their yield expressed as mg of compound/100 g of chamomile sample.

\section{Determination of antioxidant activity}

Antioxidant activity of chamomile extracts was determined using DPPH method described earlier [32]. Plant extracts were dissolved in methanol $(125 \mu \mathrm{g} / \mathrm{mL})$ and mixed with $0.3 \mathrm{mM}$ DPPH radical solution. The measurements were performed in triplicate.

The absorbance was measured at $517 \mathrm{~nm}$ and DPPH scavenging activity was determined using Eq. (1):

$$
\% \text { DPPH activity }=\frac{\left(A_{D P P H}+A_{b}\right)-A_{s}}{A_{D P P H}} * 100
$$

\section{Statistical analysis}

One-way analysis of variance (ANOVA) and multiple comparisons (Duncan's post hoc test) were used to evaluate the significant difference of the data at $p<0.05$. Data were expressed as means of replication \pm standard deviation.

\section{Results and discussion}

The chamomile extracts in this study were obtained from different chamomile fractions using four extraction techniques and the results related to obtained extraction yield and antioxidant activity of obtained extracts are given in Table 1, while results for herniarin and umbelliferone content in obtained extracts are given in Table 2.
The results show that there were significant differences $(p<0.05)$ between analysed chamomile fractions on all analysed variables. The ANOVA analysis of extraction yields and antioxidant activity of chamomile extracts (Table 1) showed the existence of four groups (different letter identifiers) which differed significantly from one to another ( $p<0.05$; Duncan's post hoc test) depending on the used chamomile fraction in the case of SFE, while soxhlet and maceration techniques showed the existence of three groups which differed significantly from one to another ( $p<0.05$; Duncan's post hoc test). Hydrodistillation show no statistically significant differences in antioxidant activity of essential oils obtained from four different fractions (one group of letter).

\section{Extraction of $M$. chamomilla processing fractions}

The greatest extraction yield was obtained using maceration technique compared to other extraction methods which reduces the extraction time and provides extracts with higher antioxidant activity (Table 1 ). In maceration process, the ethanol was chosen as the solvent based on its environmental-friendly characteristics, low cost and its ability to enhance the extraction of target compounds from vegetable materials. Ethanol in the concentration $20-100 \%(v / v)$ is the most common organic solvent used in extraction of flavonoids, phenolics, anthocyanins, lycopene, and others, from plant materials [33]. These compounds are generally more soluble in water-ethanol 
Table 1 Extraction yields and antioxidant activity of chamomile extracts

\begin{tabular}{lllll}
\hline Analysed variable/sample & \multicolumn{2}{l}{ Extraction method } & & \\
\cline { 2 - 5 } & SFE & Soxhlet & Maceration (with 50\% ethanol) & Hydrodistillation \\
\hline Extraction yield (g/100 g) & & & \\
Unprocessed chamomile flowers first class & $1.57 \pm 0.11^{\mathrm{a}}$ & $4.60 \pm 0.24^{\mathrm{a}}$ & $20.85 \pm 0.44^{\mathrm{a}}$ & $0.41 \pm 0.06^{\mathrm{a}}$ \\
Processed chamomile flowers first class & $3.64 \pm 0.16^{\mathrm{b}}$ & $4.98 \pm 0.31^{\mathrm{a}}$ & $22.30 \pm 0.77^{\mathrm{b}}$ & $0.62 \pm 0.09^{\mathrm{b}}$ \\
Processing waste & $0.23 \pm 0.07^{\mathrm{c}}$ & $3.47 \pm 0.11^{\mathrm{b}}$ & $20.60 \pm 0.51^{\mathrm{a}}$ & $0.24 \pm 0.08^{\mathrm{c}}$ \\
Pulvis & $0.97 \pm 0.08^{\mathrm{d}}$ & $1.45 \pm 0.13^{\mathrm{c}}$ & $6.70 \pm 0.34^{\mathrm{c}}$ & $0.28 \pm 0.06^{\mathrm{c}}$ \\
\% DPPH scavenging & & & & $3.9 \pm 0.10^{\mathrm{a}}$ \\
Unprocessed chamomile flowers first class & $5.1 \pm 0.13^{\mathrm{a}}$ & $2.0 \pm 0.14^{\mathrm{a}}$ & $56.0 \pm 0.82^{\mathrm{a}}$ & $3.8 \pm 0.12^{\mathrm{a}}$ \\
Processed chamomile flowers first class & $3.4 \pm 0.21^{\mathrm{b}}$ & $1.3 \pm 0.07^{\mathrm{b}}$ & $55.0 \pm 0.74^{\mathrm{a}}$ & $2.9 \pm 0.14^{\mathrm{a}}$ \\
Processing waste & $4.5 \pm 0.33^{\mathrm{c}}$ & $2.5 \pm 0.08^{\mathrm{a}}$ & $61.5 \pm 0.23^{\mathrm{b}}$ & $3.2 \pm 0.18^{\mathrm{a}}$ \\
Pulvis & $7.2 \pm 0.18^{\mathrm{d}}$ & $0.0 \pm 0.00^{\mathrm{c}}$ & $45.4 \pm 0.86^{\mathrm{c}}$ & \\
\hline
\end{tabular}

Data are expressed as mean value of replication ( $n$ )

The same letter in the same column of analysed variable indicates no significant differences (Duncan's test, $p<0.05$ )

Table 2 Umbelliferone and herniarin content in chamomile extracts

\begin{tabular}{|c|c|c|c|c|c|c|c|}
\hline \multirow[t]{2}{*}{ Analysed variable/sample } & \multirow[t]{2}{*}{ SFE } & \multirow{2}{*}{$\begin{array}{l}\text { Recovery } \\
\text { (\%) }\end{array}$} & \multicolumn{4}{|c|}{ Extraction method } & \multirow[t]{2}{*}{ Hydrodistillation } \\
\hline & & & Soxhlet & Recovery (\%) & $\begin{array}{l}\text { Maceration } \\
\text { (with } 50 \% \\
\text { ethanol) }\end{array}$ & Recovery (\%) & \\
\hline \multicolumn{8}{|l|}{ mg umbelliferone/100 g } \\
\hline $\begin{array}{l}\text { Unprocessed chamomile } \\
\text { flowers first class }\end{array}$ & $0.00^{\mathrm{a}}$ & 98.70 & $0.50 \pm 0.02^{\mathrm{a}}$ & 98.64 & $5.59 \pm 0.05^{\mathrm{a}}$ & 98.58 & $\mathrm{nd}^{\mathrm{a}}$ \\
\hline $\begin{array}{l}\text { Processed chamomile flowers } \\
\text { first class }\end{array}$ & $0.33 \pm 0.00^{b}$ & 98.32 & $0.00^{b}$ & 100.82 & $4.78 \pm 0.15^{b}$ & 97.45 & $\mathrm{nd}^{\mathrm{a}}$ \\
\hline Processing waste & $0.02 \pm 0.00^{\mathrm{a}}$ & 97.91 & $0.85 \pm 0.03^{\mathrm{a}}$ & 96.36 & $11.80 \pm 0.17^{c}$ & 98.33 & $n d^{\mathrm{a}}$ \\
\hline Pulvis & $0.32 \pm 0.02^{b}$ & 102.38 & $0.13 \pm 0.02^{c}$ & 98.82 & $5.26 \pm 0.14^{\mathrm{a}}$ & 103.42 & $n d^{\mathrm{a}}$ \\
\hline \multicolumn{8}{|l|}{ mg herniarin/100 g } \\
\hline $\begin{array}{l}\text { Unprocessed chamomile } \\
\text { flowers first class }\end{array}$ & $13.08 \pm 1.78^{\mathrm{a}}$ & 103.9 & $37.66 \pm 5.46^{a}$ & 98.1 & $47.45 \pm 5.11^{\mathrm{a}}$ & 102.8 & $<\mathrm{LOD}^{\mathrm{a}}$ \\
\hline $\begin{array}{l}\text { Processed chamomile flowers } \\
\text { first class }\end{array}$ & $37.05 \pm 6.29^{b}$ & 100.2 & $20.22 \pm 2.28^{b}$ & 93.5 & $45.54 \pm 4.16^{a}$ & 104.0 & $<\mathrm{LOD}^{\mathrm{a}}$ \\
\hline Processing waste & $2.71 \pm 0.12^{c}$ & 90.8 & $41.18 \pm 2.59^{\mathrm{a}}$ & 103.6 & $82.79 \pm 3.26^{b}$ & 97.6 & $<\mathrm{LOD}^{\mathrm{a}}$ \\
\hline Pulvis & $15.57 \pm 2.87^{b}$ & 90.6 & $5.63 \pm 0.75^{c}$ & 95.8 & $20.81 \pm 0.00^{c}$ & 103.1 & $<\mathrm{LOD}^{\mathrm{a}}$ \\
\hline
\end{tabular}

Data are expressed as mean value of replication $(n) \pm S D$

The same letter in the same column of analysed variable indicates no significant differences (Duncan's test, $p<0.05$ )

nd, not detected; $<$ LOD, below limit of detection

solutions than in pure alcohol. The highest extraction yield in maceration process was obtained from processed chamomile flowers first class, while unprocessed chamomile flowers first class and processing waste show no significant differences $(p<0.05)$ between obtained extraction yield.

There were statistically significant differences $(p<0.05)$ between extraction yields obtained by supercritical $\mathrm{CO}_{2}$ from all four chamomile fractions. The highest extraction yield was obtained from processed chamomile flowers first class $(3.64 / 100 \mathrm{~g})$. Extraction yields obtained with supercritical $\mathrm{CO}_{2}$ were more comparable to yield obtained with $n$-hexane in Soxhlet apparatus, while maceration using $50 \%$ ethanol solution provided much higher yields. This can be explained by similar dissolving capacity of supercritical $\mathrm{CO}_{2}$ and $n$-hexane because both are non-polar solvents, dissolving non polar compounds only, while ethanol as a polar solvent dissolved the whole soluble polar compounds. According to that, the SFE extraction is more selective extraction technique compared to maceration. The similar conclusion is obtained by Felfoldi-Gava et al. [34] where authors published approximately 20 times higher yield of alcoholic ethanol extracts then the SFE or $n$-hexane extracts. Roby et al. 
[35] also compared different solvents in extraction of chamomile flowers and found that the extracting ability is as follows: methanol > ethanol > diethyl ether $>$ hexane.

The highest essential oil content obtained by hydrodistillation in this study was $0.6 \%$ from processed chamomile flowers first class. Other chamomile fraction had lower essential oil content. The chamomile oil content is usually very low and varies from 0.3 to $1.5 \%$ [3], while Roby et al. [35] obtained $0.73 \%$. The obtained essential oil was characterized by blue color, while SFE extracts and extracts obtained by ethanol water solution had dark yellow colour which is in accordance with previous studies [25]. Dark yellow color indicates that no thermal degradation of the naturally occurring matricine to chamazulene has occurred. Matricine is converted upon steam distillation or exposure to heat into chamazulene, a sesquiterpene responsible for the blue colour of the distillate $[2,36]$.

Kotnik et al. [20] investigated the supercritical $\mathrm{CO}_{2}$ extraction of chamomile flower heads, and the results were compared with those obtained with Soxhlet extraction, steam distillation and maceration. Extraction yields obtained conventionally by maceration with ethanol and Soxhlet extraction were higher up to $10 \%$ then the yield obtained by SFE (3.81\%), while the yield obtained with distillation process was very low and similar with our study, $0.60 \%$. Also, chamazulene was detected only in the extract obtained by steam distillation; in other extracts was not present. Scalia et al. [26] also compared SFE with conventional extraction techniques for the isolation of the active compounds present in chamomile flower heads. The yield of essential oil obtained with supercritical $\mathrm{CO}_{2}$ was 4.4 times higher than that produced by steam distillation, similar like in our study.

Using supercritical $\mathrm{CO}_{2}$ extraction, degradation of thermolabile compounds (e.g. matricine) is minimized and the yield of volatile analytes is increased. Therefore, the possibility of producing plant extracts without any contact with conventional organic solvents and thus directly usable, makes the SFE technique an attractive alternative to the other currently used methods.

\section{Herniarin and umbelliferone content}

As $M$. chamomilla is a well-known herniarin and umbelliferone containing plant [7], many researchers have dealt with their isolation from this plant. Umbelliferone can be extracted with water [36], ethanol or aqueous ethanol [37], methanol [38], while solvents like ether or dichloromethane are not so efficient [39]. Bajerova et al. [40] compared different techniques in extraction of umbelliferone from different plants, proving that Soxhlet extraction with methanol was the most efficient one, while SFE extraction was not efficient probably due to $\mathrm{CO}_{2}$ being non polar solvent. This is in accordance with our findings in Table 1, where polar solvents are proven to be more efficient than non-polar ones, like $n$-hexane (Soxhlet) and $\mathrm{CO}_{2}$ (SFE).

The data given in Table 2 for umbelliferone content indicates that the highest umbelliferone content $(11.80 \mathrm{mg} / 100 \mathrm{~g})$ were obtained from chamomile processing waste using maceration technique and aqueous ethanol solution as a solvent. Also, the highest herniarin content $(82.79 \mathrm{mg} / 100 \mathrm{~g})$ was found to be in chamomile processing waste extract obtained by the same maceration technique. A high umbelliferone and herniarin content in the extracts obtained by maceration technique can be explained by the fact that these samples which remain after chamomile processing are mainly steam and leaves, which are also rich in these compounds, often more than flowers [7]. In the essential oils of all four chamomile fractions obtained by hydrodistillation, herniarin and umbelliferone were not detected.

The ANOVA analysis of umbelliferone and herniarin content of chamomile extracts (Table 2) showed the existence of mainly three groups which differed significantly from one to another $(p<0.05$; Duncan's post hoc test) depending on the used chamomile fraction; only in the case of hydrodistillation there were no statistically significant differences because umbelliferone content was not detected and herniarin content was below limit of detection $(<\mathrm{LOD})$ in all analysed chamomile fractions.

\section{Antioxidant activity of obtained extracts}

Furthermore, these chamomile extracts (Table 1) have also proven to possess antioxidant activity (45.4-61.5\% $\mathrm{DPPH}$ scavenging activity). This was expected, since polar solvents are more effective in extraction of polar compounds, like polyphenols, which greatly contribute to antioxidant activity. Bajerova et al. [40] also found that extracts of chamomile obtained with polar solvents possess better antioxidant activity than SFE extracts. Also, Formisano et al. [41] compared antioxidant activity of methanolic chamomile extracts and essential oil and found that methanolic extracts showed much better activity than essential oils, presuming that methanolic extracts are richer in phenols, thus contributing to antioxidant activity. This was also observed in our investigation, where SFE extracts did not show any significant antioxidant activity and neither did the hexane extracts, which is expected, since $\mathrm{CO}_{2}$ and hexane possess a similar dissolving capacity. The antioxidant activity of essential oils obtained by hydrodistillation was also low and not comparable to ethanol extracts. 


\section{Conclusions}

Processing waste which remains after chamomile processing in significant amounts can be considered as a rich source of coumarin derivatives-herniarin and umbelliferone. Umbelliferone is often used in cosmetic industry due to its strong absorption of UV light and for its extraction from plant material different extraction techniques can be employed. Hereby, in this research we compared SFE, hexane and ethanol extraction (maceration) and hydrodistillation and proved that aqueous ethanol is the most effective in this regard. These extracts not only had the highest umbelliferone and herniarin content, but also showed a significant antioxidant activity. For potential utilization in cosmetic industry it would be interesting to obtain extracts with high umbelliferone and herniarin content and antioxidant activity as additives to different cosmetic products.

\section{Authors' contributions}

MM, SJ, DS, and IB designed the experiments. MM, SJ and NM performed the experiments. MM, SJ, and IB analyzed the data. All the authors discussed and planned the paper. MM and SJ drafted the manuscript. All authors read and approved the final manuscript.

\section{Acknowledgements}

The authors are grateful to the Josip Juraj Strossmayer University of Osijek, Republic of Croatia for financial support.

\section{Competing interests}

The authors declare that they have no competing interests.

\section{Publisher's Note}

Springer Nature remains neutral with regard to jurisdictional claims in published maps and institutional affiliations.

Received: 8 February 2017 Accepted: 28 July 2017

Published online: 05 August 2017

\section{References}

1. Schilcher H, Imming P, Goeters S (2005) Pharmacology and toxicology. In: Franke R, Schilcher H (eds) Chamomile industrial profiles. CRC Press, Boca Raton, pp 251-265

2. Singh O, Khanam Z, Misra N, Srivastava MK (2011) Chamomile (Matricaria chamomilla L.): an overview. Pharmacogn Rev 5:82-95

3. Schilcher H, Imming P, Goeters S (2005) Active chemical constituents of Matricaria chamomilla L. syn. Chamomilla recutita (L.) Rauschert. In: Franke $\mathrm{R}$, Schilcher $\mathrm{H}$ (eds) Chamomile industrial profiles. CRC Press, Boca Raton, pp 65-83

4. Iverson CD, Zahid S, Li Y, Shoqafi AH, Ata A, Samarasekera R (2010) Glutathione S-transferase inhibitory, free radical scavenging, and antileishmanial activities of chemical constituents of Artocarpus nobilis and Matricaria chamomilla. Phytochem Lett 3:207-211

5. Kotov AG, Khvorost PP, Komissarenko NF (1991) Coumarins of Matricaria recutita. Chem Nat Compd 27:853-854

6. Novakova L, Vildova A, Mateus JP, Goncalves T, Solich P (2010) Development and application of UHPLC-MS/MS method for the determination of phenolic compounds in Chamomile flowers and Chamomile tea extracts. Talanta 82:1271-1280

7. Petrulova-Poracka V, Repcak M, Vilkova M, Imrich J (2013) Coumarins of Matricaria chamomilla L.: aglycones and glycosides. Food Chem 141:54-59
8. Repcak M, Suvak M (2013) Methyl jasmonate and Echinothrips americanus regulate coumarin accumulation in leaves of Matricaria chamomilla. Biochem Syst Ecol 47:38-41

9. Repcak M, Imrich J, Franekova M (2001) Umbelliferone, a stress metabolite of Chamomilla recutita (L.) Rauschert. J Plant Physiol 158:1085-1087

10. Eliašova A, Repčak M, Pastirova M (2004) Quantitative changes of secondary metabolites of Matricaria chamomillaby abiotic stress. Z Naturforsch 59:543-548

11. Heldmaier M, Beyer-Koschitzke J, Stahl-Biskup E (2009) Oil extracts of herbal drugs-optimisation of the extraction parameters. Pharmazie 64:403-406

12. Pietta P (1987) Simultaneous isocratic high-performance liquid chromatographic determination of flavones and coumarins in Matricaria chamomilla extracts. J Chromatogr 404:279-281

13. Schulz H, Albroscheit $G$ (1988) High-performance liquid chromatographic characterization of some medical plant extracts used in cosmetic formulas. J Chromatogr 442:353-361

14. Redaelli C, Formentini L, Santaniello E (1981) HPLC determination of coumarins in Matricaria chamomilla. Planta Med 43:412-413

15. Silvan AM, Abad MJ, Bermejo P, Sollhuber M, Villar A (1996) Antiinflammatory activity of coumarins from Santolina oblongifolia. J Nat Prod 59:1183-1185

16. Bourinbaiar AS, Tan X, Nagorny R (1993) Inhibitory effect of coumarins on HIV-1 replication and cell-mediated or cell-free viral transmission. Acta Virol 37:241-250

17. Weber US, Steffen B, Siegers CP (1998) Antitumor-activities of coumarin, 7-hydroxy-coumarin and its glucuronide in several human tumor cell lines. Res Commun Mol Path 99:193-206

18. Sarkar R, Arora P, Garg KV (2013) Cosmeceuticals for hyperpigmentation: what is available? J Cutan Aesthet Surg 6:4-11

19. Kiełbus M, Skalicka-Woźniak K, Grabarska A, Jeleniewicz W, DmoszyńskaGraniczka M, Marston A, Polberg K, Gawda P, Klatka J, Stepulak A (2013) 7-Substituted coumarins inhibit proliferation and migration of laryngeal cancer cells in vitro. Anticanc Res 33:4347-4356

20. Kotnik P, Škerget M, Knez Ž (2007) Supercritical fluid extraction of chamomile flower heads: comparison with conventional extraction, kinetics and scale-up. J Supercrit Fluids 43:192-198

21. Jokić S, Vidović S, Aladić K (2014) Supercritical fluid extraction of edible oils. In: Osborne J (ed) Supercritical fluids: fundamentals, properties and applications. Nova Science Publishers Inc, New York, pp 205-228

22. Stahl E, Schutz E (1978) Extraktion der Kamillenblüten mit überkritischen Gasen. Arch Pharm 311:992-1001

23. Vuorela H, Holm Y, Hiltunen R, Harvala T, Laitinen A (1990) Extraction of the volatile oil in chamomile flowerheads using supercritical carbon dioxide. Flavour Fragr J 5:81-84

24. Smith RM, Burford MD (1994) GLC of supercritical fluid extracts of essential oils from the medicinal herbs, Feverfew, Tansy, and German Chamomile. J Chromatogr Sci 32:265-269

25. Reverchon E, Senatore F (1994) Supercritical carbon dioxide extraction of chamomile essential oil and its analysis by gas chromatography-mass spectrometry. J Agr Food Chem 42:154-158

26. Scalia S, Giuffreda L, Pallado P (1999) Analytical and preparative supercritical fluid extraction of Chamomile flowers and its comparison with conventional methods. J Pharmaceut Biomed 21:549-558

27. Kaiser CS, Römpp H, Schmidt PC (2004) Supercritical carbon dioxide extraction of chamomile flowers: extraction efficiency, stability, and in-line inclusion of chamomile-carbon dioxide extract in $\beta$-cyclodextrin. Phytochem Anal 15:249-256

28. Pekić B, Zeković Z, Petrović L, Tolić A (1995) Behavior of (-)-a-Bisabolol and (-)-a-bisabololoxides $A$ and $B$ in chamomile flower extraction with supercritical carbon dioxide. Separ Sci Technol 30:3567-3576

29. Povh NP, Marques MOM, Meireles MAA (2001) Supercritical $\mathrm{CO}_{2}$ extraction of essential oil and oleoresin from chamomile (Chamomilla recutita [L.] Rauschert). J Supercrit Fluids 21:245-256

30. Zeković Z (2000) Chamomile ligulate flowers in supercritical $\mathrm{CO}_{2}$-extraction. J Essent Oil Res 12:85-93

31. Jokić S, Horvat G, Aladić K (2015) Design of SFE system using a holistic approach_problems and challenges. In: Lindy J (ed) Supercritical fluid extraction: technology, applications and limitations. Nova Science Publishers Inc., New York, pp 95-122 
32. Jokić S, Bijuk M, Aladić K, Bilić M, Molnar M (2016) Optimization of supercritical $\mathrm{CO}_{2}$ extraction of grape seed oil using response surface methodology. Int J Food Sci Tech 51:403-410

33. Spigno G, Tramelli L, Faveri DMD (2007) Effects of extraction time, temperature and solvent on concentration and antioxidant activity of grape marc phenolics. J Food Eng 81:200-208

34. Felfoldi-Gava A, Szarka S, Simandi B, Blazics B, Simon B, Kary A (2012) Supercritical fluid extraction of Alnus glutinosa (L.) Gaertn. J Supercrit Fluids 61:55-61

35. Roby MHH, Sarhana MA, Selima KAH, Khalel KI (2013) Antioxidant and antimicrobial activities of essential oil and extracts of fennel (Foeniculum vulgare L.) and chamomile (Matricaria chamomilla L.). Ind Crop Prod 44:437-445

36. Ness A, Metzger JW, Schmidt PC (1996) Isolation, identification and stability of 8-desacetylmatricine, a new degradation production product of matricine. Pharm Acta Helv 71:265-271

37. Chanfrau JER, Ferrada CR (2014) Harvest time influences on coumarin and umbelliferone contents in extracts of Justicia pectoralis Jacq. (tilo). Rev Cuba Farm 48:477-485
38. Lj Stanojevic, Stankovic M, Lj Nikolic, Nikolic V (2007) The influence of the operation conditions and the extraction techniques on the yield, kinetics and composition of ethanol extracts of Hieracium pilosella L. Chem Ind Chem Eng Q 13:199-204

39. Skalicka-Wozniak K, Głowniak K (2012) Pressurized liquid extraction of coumarins from fruits of Heracleum leskowii with application of solvents with different polarity under increasing temperature. Molecules 17:4133-4141

40. Bajerova P, Adam M, Bajer T, Ventura K (2014) Comparison of various techniques for the extraction and determination of antioxidants in plants. J Sep Sci 37:835-844

41. Formisano C, Delfine S, Oliviero F, Tenore GC, Rigano D, Senatore F (2015) Correlation among environmental factors, chemical composition and antioxidative properties of essential oil and extracts of chamomile (Matricaria chamomilla L.) collected in Molise (South-central Italy). Ind Crop Prod 63:256-263

\section{Submit your manuscript to a SpringerOpen ${ }^{\circ}$ journal and benefit from:}

- Convenient online submission

- Rigorous peer review

- Open access: articles freely available online

- High visibility within the field

- Retaining the copyright to your article

Submit your next manuscript at $\boldsymbol{\nabla}$ springeropen.com 